\title{
Survey Methodology to Ensure Appropriate Data Collection: CELAC's Firms' Beyond the Region
}

\author{
S. Rick Fernandez \\ School of Management, Shanghai University, Shanghai, China \\ School of Management, Shanghai University \\ 99 Shanda Road, Shanghai 200444, China. \\ Tel: 86-138-1793-1651. E-mail: saulrick@163.com
}

Accepted: Sep 03, 2013 Published: October 10, 2013

Doi:10.5296/jsr.v4i2.4402ＵRL: http://dx.doi.org/10.5296/jsr.v4i2.4402

\begin{abstract}
This paper proposes an innovation in the implementation of Commercial Cluster Integration according to drive a firms survey in networking management. As an extension of Latin American firms into other potential markets, it provides a scenario of countries integration with the aim of reducing multiple international value cost, and delivery timing (Just-in-time) in the framework of Supply Chain Management, contributing to the issue of innovating cluster networking with the scope of developing the market chain survey.

The Author proposes that Latin American firms should work in a cooperation unit, with their governments to build the integration. This study explains the reason why; it makes sense for a Commercial Cluster Platform to enter to an external supply chain.
\end{abstract}

Keywords: Supply Chain, Survey, CELAC, Integration, Cluster, Commercial 


\section{Macrothink}

\section{Introduction}

- Cross functional teams - engineering, procurement, marketing, tendering, accounting

- Supply chains - management and development to ensure competitiveness

- Partnerships and alliances - relationships may be either mutually beneficial open relationships or the creation of a separate legal entity called a joint venture (e.g. capital goods for the oil industry).

\section{Objective of the Study}

- Understand the concept of the supply chain, its importance, and management.

- Describe the problems of managing the supply chain and some innovative solutions.

- Trace the evolution of software that supports activities along the supply chain.

- Define business-processing reengineering (BPR) and understand its relationship with the supply chain.

- Describe the networked organization and identify its benefits.

- Demonstrate the role of IT in supporting BPR.

- Describe mass customization, cycle time reduction, self-directed teams, and empowerment.

- Define business alliances and virtual corporations.

- Understand the relationships among enterprise resources planning (ERP), supply chain management (SCM), and electronic commerce.

\section{Purpose of the Study}

World-class companies expect supply chain management to focus on the following value adding outputs:

- Quality - purchased materials and services should be virtually defecting free. Many defects can be traced back to buy in items.

- Cost - minimisation of total cost of acquiring, transporting, holding, converting items as well as quality costs.

- Time - need to minimise time to market for new products as well as minimising lead-times to increase flexibility.

- Technology - ensuring that the firm's supply base provides appropriate technology in a timely manner; ensuring that technology associated with core competence is carefully controlled.

- Continuity of supply - need to reduce risk of supply disruptions. These may have impact on other functions (aluminium vs. carbon fibre reinforced plastics in the 
aerospace industry). May involve the development of alliances.

\section{Significance of the Study}

- Integration - the firm's supply chain strategy should be integrated with marketing, production and financial strategies.

- Business environment - supply chain must address the identification of threats and opportunities (with particular reference to suppliers and customers).

- Technology - access and control, avoid turning suppliers into competitors.

- Information systems - need timely, accurate and cost effective transfer of information with buyers and suppliers (e.g. electronic data interchange).

- Value chain - need to ensure that the value chain of which the company is a part is competitive (e.g. careful management of margins through the supply chain)

- Analysis - concentrate on high value items - decentralise decision making for low value items.

\section{Results}

- Productivity improvement

- Increases customer satisfaction

- Become the number one PC seller

- Be considered one of the world's best-managed and profitable companies

\section{Power Relationships}

- In many cases "collaborative" relationships are underpinned by strong buyer control, enforced through vetting and monitoring

- Powerful buyers impose terms on weaker dependent suppliers (e.g. supermarkets)

- Research has concentrated upon focal producers able to exert a significant degree of control over smaller suppliers (e.g. automotive companies)

- Other sectors such as engineer-to-order, low volume manufacture may have different power relationships.

- Adversarial relationships proved counter productive to both parties.

- By 1980's a partnership model was being adopted to reduce costs, resolve scheduling problems and other technical difficulties.

- Strategic change was required to implement total quality principles and JIT.

- The partnership, or obligational model, is characterised by close operational and strategic links between buyer and supplier; the provision of technical and managed assistance to suppliers and the establishment of preferred supplier status or single 
sourcing agreements.

\subsection{Direction on Commercial Processes}

Fundamentally rethinking and radically redesigning business processes, in order to achieve dramatic improvements in quality, cost, speed and service

Table 1. Coordinate an Operation

\section{Vendors,}

Suppliers

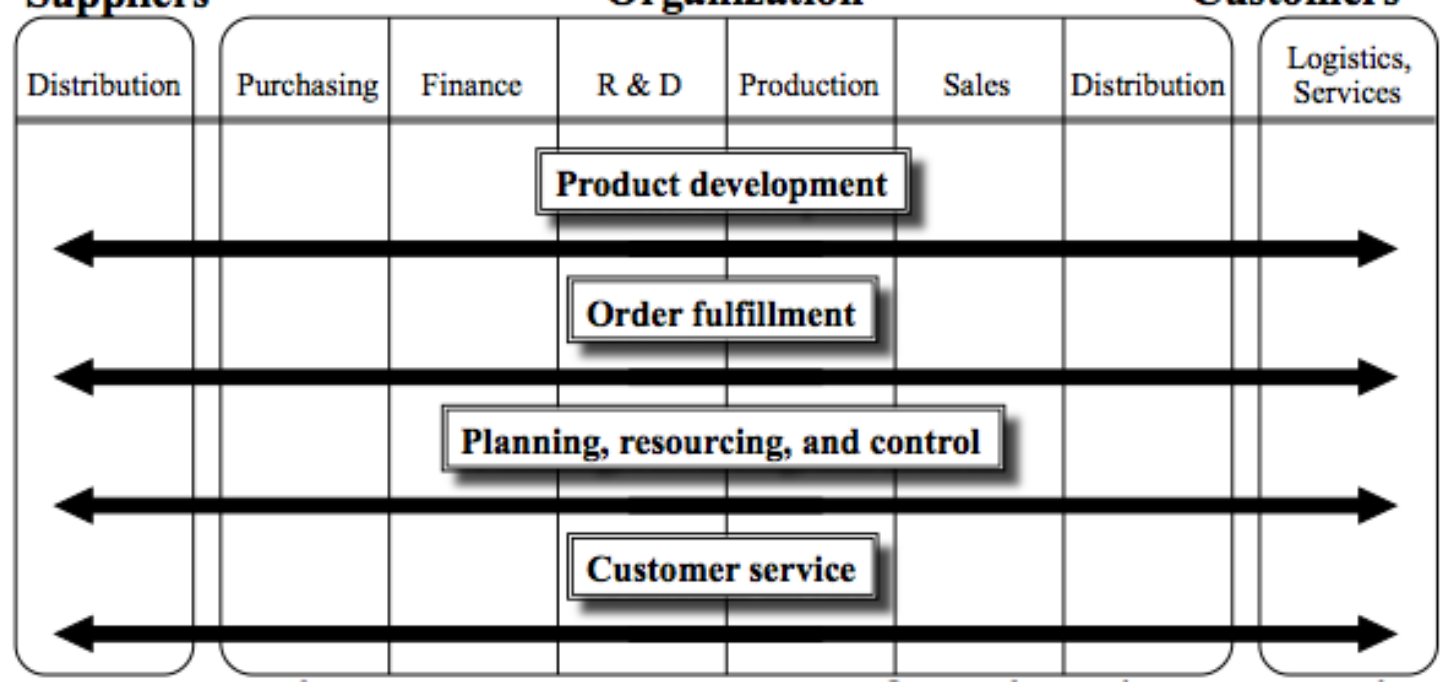

Sources: Author Illustration

\section{- $\quad$ Three Cs}

3. Customers today know what they want, what they are willing to pay, and how to get products and services on their own terms.

4. Competition is continuously increasing with respect to price, quality, selection, service, and promptness of delivery.

5. Change continues to occur. Markets, products, services, technology, the business environment, and people keep changing, frequently in an unpredictable and significant manner.

\subsection{RESEARCH METHODOLOGY}

As already mentioned in previous sections, to date no researches have been found related study as commercial clusters implementation, with special focus on economic group (e.g. CELAC) jointly developing a massive commercial integration. However, there are no studies that have considered Commercial Cluster Integration platform across the New Latin American Economic Group (CELAC), which proposes to integrate CELAC countries as commercial platform, in order to enter with greater force with investment size, target market knowledge, production levels, as well as international logistics supply chain into other markets. In fact, there is little literature to display this type of study focused on Commercial Cluster Integration platform implementation, which in this study is related among f CELAC's 
firms. Therefore, this study is designed with two different purposes:

a. On one hand, to be exploratory study into the Commercial Cluster Integration platform implementation by firms of (CELAC)

b. And on the other hand, to be explanatory study, where government-networking support must to be an essential part in international politics relation.

The theoretical model that was developed in following section addressed the study questions. This exercise also provides richness of contextual detail permitting grounding of the framework. Then, the data collected allowed the hypotheses mentioned in previous section to be tested.

\subsection{Research Design \& Sampling Methods}

The survey was carried out with a cross-sectional design in which, the data were collected in two different times. This study was implemented in both:

a. Qualitative Analysis

b. And Quantitative Method

Information was conducted in the form of study field by distributing self-administered questionnaires and interviews. The purpose of the qualitative analysis is to discover, how the effectiveness of knowledge transfer is affected by the measures. At the same time, the quantitative method, which is more, involved statistical and using rudimentary programs to analyze data, in order to confirm the findings of the qualitative analysis, implementing mathematical analysis. On the other hand, the proposed determinant factors, and the results of the quantitative analysis could be clarified and, supplemented by a qualitative approach to achieve a more credible conclusion.

\subsubsection{Market Integration Analysis}

Based on related theories and empirical research, this study aims to consolidate and expand the existing few literatures on integration network among Commercial Cluster Integration's firms, and to contribute a wider body of literature to firms integration network.

The criteria of industry selection in this study are from the main commercial clusters implementation by CELAC firms. The questionnaire study provides that governments must support group firm's cooperation, in order to improve wellness in international markets competitiveness and productivity.

S. Rick Fernandez., (2013: 103-121), confirm the database was drawn from firms of CELAC region that are involved in regional commercial, and international integration network. The 424 respondent firms derived from the Bureau Chamber of Commerce of several countries (CELAC), and were screened to identify every single firm's measures of implementation, with government network, supporting the project that this study proposed during the study period 2010 - 2013. Samples were selected from the most current information. Every attempt was made to append the latest list of Commercial Cluster Integration network, in order to get the most up-to-date picture of the samples studied. Were screened from the 424 involved firms. The redundant firms were discarded from the lists; 224 from production and 
commercial firms taken from several countries database (CELAC), 45 services firms from the lists, 32 exporting firms and 15 importing firms. Thus, the total amount of firms of the study was 316 . Table 3.1 presents the number of firms.-

Table 3.1. Firms of the Case Study

\begin{tabular}{lcc}
\hline Kind of Firms & Firms Participation & $\%$ \\
\hline Production Firms & 125 & 39.56 \\
Commercial Firms & 99 & 31.33 \\
Services Firms & 45 & 14.24 \\
Exporting Firms & 32 & 10.13 \\
Importing Firms & 15 & 4.75 \\
Total & 316 & 100 \\
\hline
\end{tabular}

Sources: S. Rick Fernandez.,2013:p.116

The commercial cluster project consists of different regional firms, and governments that are in charge of different tasks concerning in the Commercial Cluster Integration networks. The respondents are: manager projects who engage commercial clusters coordinator in the firm and directors of commercial cluster projects. Project coordinators were asked to select projects that came to their attention recently. Measures were developed and refined on the basis of the guidelines provided by Churchill (1979: 64-73) and Gerbing and Anderson (1988: 186-192). The questionnaires were used to ask the respondents about their experiences with integration network. The data used in the analyses were collected with an e-mail survey, during the period of December 2011 to December 2012.

The measures used were designed to examine conditions of regional firms (CELAC), and possibilities for implementing a commercial cluster platform with governments support. The data were collected from Latin American and the Caribbean firms viewpoints, through e-mail surveys. However, the in-depth interview was mostly conducted from firms' perspectives and commercial clusters behavior. In addition, Lambe et al. (2002: 141-158) stated, that although researchers widely recognize the value of relevant data from firms that are using commercial network, the difficulties associated with gathering and using such data are so great (Menon et al., 1995: 77-84).

\subsubsection{Sampling Techniques}

Although some kind of sampling plan should be used to identify the appropriate sample size, this study used the entire population instead. This is due to the nature of the questions of this study, which data were to be analyzed by factor analysis and structural equation modeling analysis. In relation to these two techniques, Hair et al. (1995) mentioned that the researcher generally would not analyze a sample of fewer than 50 observations, and preferably the sample size should be 100 or larger. As a general rule, the minimum was to have at least five observations for each independent variable, or five times as many variables observations there are to be analyzed, and the more acceptable range would be a ten-to-one ratio. In 
relation to the structural equation model testing, a general rule is that there should be five observations for each independent variable (S. Rick Fernandez., 2013: 103-121).

The questionnaires were sent to the sampling firms respondents (CELAC), while in-depth interviews were undertaken through a purposive sampling and using a snowball technique. Those firms were chosen on the basis of their involvement and knowledge about the Commercial Cluster Integration, in terms of international supply chain. The purpose of gathering data from the interviews was to get firms opinions and describe the deeper, and more detailed facets of the situations in their responsibilities, dealing according to the commercial clusters implementation network. The purposive sample is arbitrarily selected, because the researchers wanted to get only the persons involved directly in the working on commercial relation.

\subsection{Methods of Data Collection}

Based on the purposes of this study, several main sources of information have been used.

Information data of the firms, operating across several industries was collected through industrial associations, such as chambers of commerce, Council of International Commerce, where one could manage and get relevant firms information according to the questionnaire. These are the best data resources of CELAC countries. The aim was to create a preliminary list of firms, and analyze relevant information of commercial clusters implementation environment at the regional level, which exhibit characteristics of transaction costs, implementation reasons, truth, commercial growth, government support, benefits, etc.... In case where no enough information available, contact was made with the firms to collect or reconfirm data.

The questionnaires were mailed to the target firms. Cover letters were sent with the questionnaires confirming the respondents involved in the commercial cluster implementation questions, stressing the importance of the study, the importance of the respondent's participation, and offering an incentive for participating. To maximize response, the e-mail survey methods suggested by Dillman (1978) were utilized in the study. Two weeks after the initial mailing, a second follow-up letter, plus a replacement questionnaire were sent to all remaining non-respondents.

Internet sources also were used in the research to collect important information related to the case study.

The final count of total firms was 424 on the lists with possible commercial cluster platform implementation. The original pre-qualified database of 424 was modified to a final total of 316 , through a process of qualifying the informants (as having experience with commercial cluster platform implementation) using e-mail, phone calls, and mailing (in the cases that were necessary). The redundant firms names were also discarded. The final response was 185 surveys returned, 174 being usable (55.1\%) was drive by S. Rick Fernandez.,(2013: 103-121). 


\section{Mll Macrothink}

\subsubsection{Response Rate}

In an effort to increase the response rate, a modified version of Dillman's (1978) total design method was followed. All mailing included a cover letter. Two weeks after the initial mailing, reminder postcards were sent to all potential respondents. For those who did not respond, a second mailing of surveys with cover letters was sent approximately 30 days after the initial mailing. After the screening of the redundant enterprises, of the first 226 surveys mailed, 18 were returned because of address discrepancies and non-contacted persons. From the resulting sample size of 208, a total of 111 first responses were received, resulting in a response rate of 53.4\%. Thus, the follow-up of 108 questionnaires was randomly resent to those who didn't return the questionnaires.

With follow-up, the surveys for 74 firms were returned. However, a lot of questionnaires were not mailed back (in these cases they were followed up again by phone). This study found that some firms did not pay any attention but some did. Total of returned questionnaires were 185, resulted in a response rate of 58,5\%. However, of these, 11 questionnaires were discarded, 4 declined to response because the firms had never experienced any Commercial Cluster Integration platform and another 7 questionnaires were not usable due to non-completion of questions (S. Rick Fernandez., 2013: 103-121).

Finally, a total of completed questionnaires were 174, resulted in a usable response rate of $55.1 \%$. Table 3.2 shows the distribution result of these enterprises according to their sector.

Table 3.2. Mail Survey Results

\begin{tabular}{lcc}
\hline Description & Quantity & $\%$ \\
\hline Questionnaires sent (1) & 226 & $8.0 \%$ \\
Undeliverable Questionnaires & 18 & $49.1 \%$ \\
Received Questionnaires (1) & 111 & $47.8 \%$ \\
Questionnaires sent for follow-up & 108 & $32.7 \%$ \\
Questionnaires received (2) & 74 & \\
Total Questionnaires sent (1) - (2) & $\mathbf{3 1 6}$ & $41.5 \%$ \\
No response & 131 & $58.5 \%$ \\
Response & 185 & $1.3 \%$ \\
Decline to participate & 4 & $2.2 \%$ \\
Unusable & 7 & $\mathbf{5 5 . 1 \%}$ \\
Completed Questionnaires & $\mathbf{1 7 4}$ & \\
\hline
\end{tabular}

Sources: S. Rick Fernandez., (2013: p.117), calculation 


\section{Macrothink}

\subsubsection{Non-Bias Testing Between Early \& Follow-Up Main Response}

For the matter, questionnaires were collected three times; Clark and Fujimoto (1991) suggested that if there is appreciable non-response, investigators should attempt to evaluate non-response subjects compared to subjects for whom data exist. One common check is to compare the demographic characteristics of the sample, with those of the population available to quote. Armstrong and Overton (1977: 396- 402), described information received from companies who respond only after repeated contacts resemble that of non-respondents. For the comparison of early and late respondents, the sample was divided into early (approximately $60 \%$ of the sample, $\mathrm{n} 1=111$ ) versus late (approximately $40 \%$ of the sample, $\mathrm{n} 2=74$ ), depending on whether their responses were received in the first or second collection process.

\subsection{Methods of Analysis}

\subsubsection{Qualitative Analysis}

The data obtained by questionnaires were synthesized using two ways of getting more understandable information result. In order to achieve these aims, two techniques were implemented to analyze the data: domain analysis and componential analysis.

a. Domain analysis is undertaken by data indexing from the available information (e.g. case studies examined from the regional firms (CELAC)), classifying the information into a group of relevant setting topic or a set of criteria according to the common qualities of the data obtained.

b. Componential analysis is also implemented with the aim of gathering information into the same component and, making comparison of similarities and differences among the overall data obtained.

\subsubsection{Quantitative Analysis}

Data was analyzed using the ordinary software, which was useful to test the non-biased analysis between early and follow-up survey, analyzing their characteristics as well as opinions of the respondents.

\subsection{Data Analysis Procedures}

The data analysis described above is presented in two parts as follow:

First part: The characteristics obtained from samples of the firms surveyed and taxonomies presented in Commercial Cluster Integration platform, were evaluated as descriptive statistics and standard deviation. In this study, the data obtained during the survey were analyzed with the help of ordinary program. Descriptive statistics such as mean, average, and frequency were used to describe the general characteristics of the respondents and, variables. In order to describe the variables in this study of Commercial Cluster Integration network (S. Rick Fernandez., 2013: 103-121), the interpretation of mean scores of each variable was retrieved from the following formula. 
Formula 1.10. Measurement Scale

Linkert Scales $=\frac{\text { Maximum scores }- \text { Minimum scores }}{5 \text { scales (strongly agree }- \text { strongly disagree) }}$ Score Interval $=\bar{X} \frac{5-1}{5}=0.8$

Table 3.3. Measurement Scales

\begin{tabular}{ll}
\hline \multicolumn{1}{c}{ Measurement Scale } & Score $(\overline{\mathrm{X}})$ \\
\hline Strongly disagree/ extremely low & $1.00-1.80$ \\
Disagree/ Low & $2.00-2.60$ \\
Neither agree or disagree/ Moderate & $3.00-3.40$ \\
Agree/ High & $4.00-4.20$ \\
Strongly disagree/ extremely high & $4.21-5.00$ \\
\hline
\end{tabular}

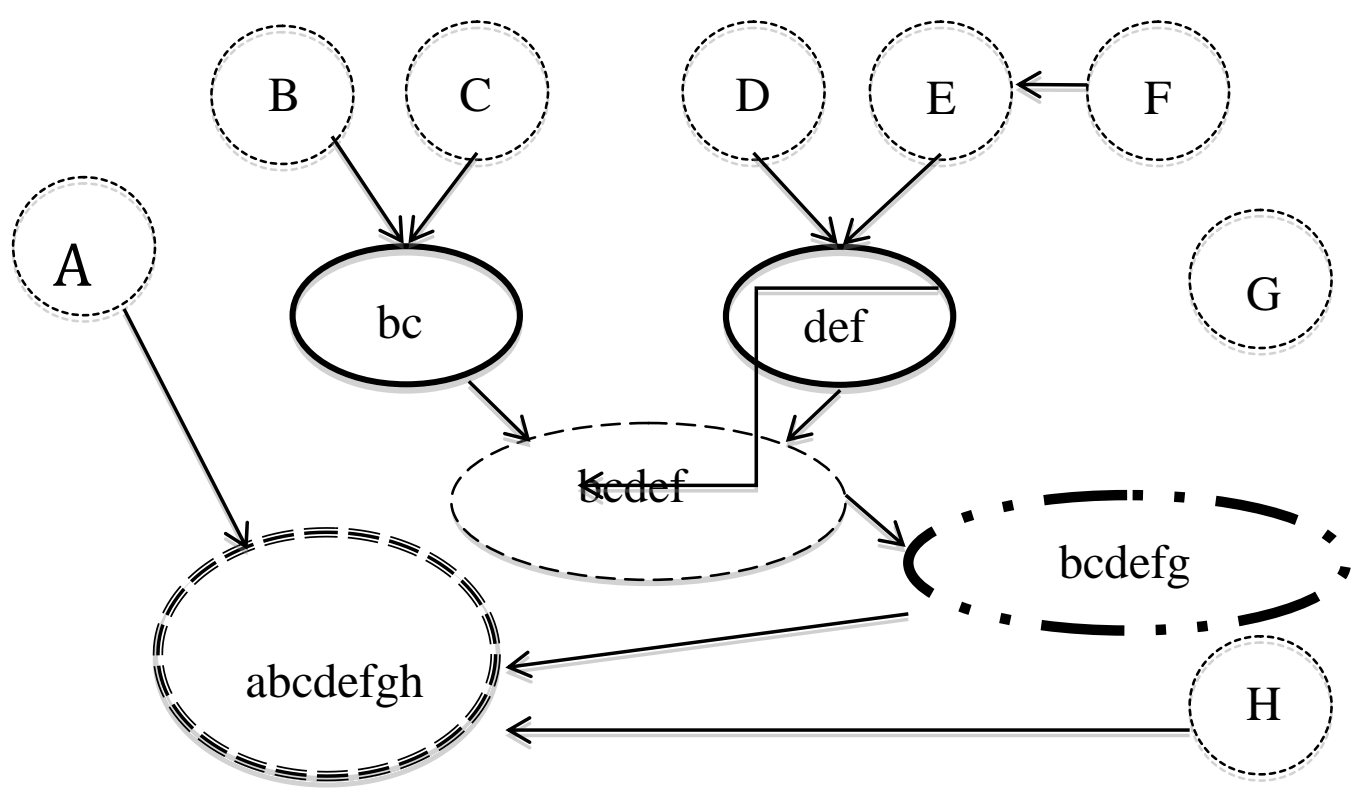

Figure 3.1. Commercial Cluster Integration network platform model, author contextualizing data (2012)

In order to explain the cause-effect relations of the factors affecting the project of commercial cluster integration network platform.

\subsection{Study Instrument}

The two data collection methods employed was: Documents studies from secondary data collection, doing structured interviews, and self-administered questionnaire. 


\subsubsection{Documentary Study \& Secondary Data}

Information on commercial cluster integration platform in terms of profiles of firms integration network, scholars and academic output were obtained from studied documents, chambers of commerce published documents, library at Shanghai University and Tsinghua University, and Latin American firms directory.

\subsubsection{Self-Administered Questionnaire}

This study on Commercial Cluster Integration platform used a questionnaire as the instrument for data collection (a measure analysis). The measure development began with a literature review and questionnaire firms. The in-depth questionnaires of the authors and commercial cluster project coordinator were managed, to help define the scope and content of the measures. Executives and authors whose could give questionnaire were approach. The cover letters approved by school of management science, were sent as references to identify the purposes and scope of the study.

In the survey the self-administered questionnaires are designed as closed-ended questions. The authors tried to select questions that corresponded to the study aims and the hypotheses, to be proven. Most measures of the questionnaire were newly developed and some were adapted and obtained from previous studies.

The questionnaire was written in Spanish. Measures from previous studies, which were originally written in Spanish, were translated into English. Two Colombian readers who had studied at Tsinghua University and Spain (Master, EOI Business School of Industrial Organization) and who were unfamiliar with the study reviewed the questionnaires. After the review, selected readers suggested several further correction of the translated version.

A five-point Likert scale with endpoints of "strongly disagree" and "strongly agree" was used to measure the items. The behavior study implementation of a commercial cluster platform was measured using five-point Likert scales, with end points of extremely low, low, neither low nor high, high and extremely high, to specify the level of the respondents' attitudes.

However, with the limit of time, and being the study a pilot project to construct and, to test the trust of the questionnaire measurement, the samples collected were gathered for several cases. The respondents were asked to answer the questionnaires and then their responses were analyzed using ordinary software, in order to evaluate the possibility implementation by regional governments (CELAC). There were comments on several questions. The questionnaire was revised according to the results of reliability testing, and submitted to three executives and two doctoral candidates whom were asked to answer and comment on it. No further comments among respondents were suggested. A mail survey, then, was conducted.

\section{Conclusion}

- Large batch and flow line systems generally exhibit the characteristics of standardisation of products, repetitive manufacturing and assembly processes that are necessary to allow the full application of JIT techniques.

- Some techniques such as supplier quality certification and point of use delivery may 
far broader applicability.

- Development of partnership relationships may require a significant volume of business.

- The impetus for product development may reside with either the buyer or the supplier.

\section{Acknowledgement}

Dr. S. Rick Fernandez was born in Cali City - Colombia on July 9, 1977. He moved as a child with his family to the Archipielago of San Andres, Old Providence and St. Catalina Colombia where is RAIZAL, Island considered by UNESCO as Biosphere Reserve. In high middle school, he played basketball and football.

He is Ph.D. Scholarship holder from Shanghai University (Shanghai, China) in Management - Emphasis in Commercial Cluster Integration “Taking CELAC's Firms' as Example into the Research Case". He has been awarded Master in International Commerce from Shanghai University (Shanghai, China) and graduated from Santiago de Cali University (Cali, Colombia) with a bachelor degree in Finance and International Business.

Dr. Fernandez served at the Ministry of Environmental Protection (MEPFECO), as Advisory Expert and Evaluator Risk, SINOCHEM AGRO, as Commercial International Relation Manager, both in China; SANTO THOMAS University and National Service for Learning SENA, as Lecturer, both in Colombia. He is an expert advisor to international firms, and is the author of a Book entitled "Establishing an FTA Between China and Colombia" (Propuesta para Implementar TLC entre China y Colombia "into spanish), including several international articles published in (Canada, United States, Singapore, Germany and Kenya). S. Rick as an author of several articles is an ad-hoc reviewer to the International Business Review from UK (SSCI Journal), also was a lecturer at The 4th African International Business and Management (AIBUMA 2013) Conference at University of Nairobi - Kenya

Thank you to Shanghai University to provide study support as well to Colombia Embassy in China, as Carmenza Jaramillo Gutierrez actual Colombia Ambassador in China. Also, I appreciate CSC Scholarship Organization to give me this incredible support to finish my studies (Ph.D.).

\section{References}

Armstrong, J. S., \& Overton, T. S. (1977). Estimating nonresponse bias in mail surveys. Journal of Marketing Research, XIV (August 1977), 396-402.

Clark, K.B. and Fujimoto, T. (1991), Product Development Performance, Harvard Business School Press, Boston, MA.

Churchill, Gilbert A., Jr. (1979), “A Paradigm for Developing Better Measures of Marketing Constructs," Journal of Marketing Research, 16 (February), 64-73.

Dillman, D. A. 1978. Mail and Telephone Surveys: The Total Design Method. New York: 
Wiley \& Sons.

Gerbing, D. and J. Anderson (1988), “An Updated Paradigm for Scale Development Incorporating Unidimensionality and Its Assessment," Journal of Marketing Research, 25 (May), 186-192.

Lambe, C.J., Spekman, R.E. and Hunt, S.D. (2002). Alliance competence, resources, and alliance suc- cess: conceptualization, measurement, and initial test. Journal of the Academy of Marketing Science, 30(2), 141-158.

Menon, Geeta, Barbara Bickart, Seymour Sudman, and Johnny Blair. 1995. "How Well Do You Know Your Partner? Strategies for Formu- lating Proxy-Reports and Their Effects on Convergence to Self-Re- ports." Journal of Marketing Research 32 (1): 77-84.

S. Rick Fernandez., (2013) Initiative Analysis to Enter into Potential and Restricted Market: Small, Medium and Largest Enterprises Having Chance into a Virgin Market: Latin American (CELAC) and China (Practical, China Case), International journal of business and management, 8(3)103-121

\section{Glossary}

BPR: business-processing reengineering

CELAC: Community of Latin American and Caribbean States

ERP: enterprise resources planning

JIT: Just-in-Time

SCM: supply chain management

\section{Appendix}

Appendix 1. Survey Question for Mobilephone Marketing

Name of the person that answers this questionnaire:

Present Enterprise Name :( ) Location :( )

Position in the Enterprise:

E-mail: ( ) Phone: ( ) Fax: ( )

Please describe your personal characteristics:

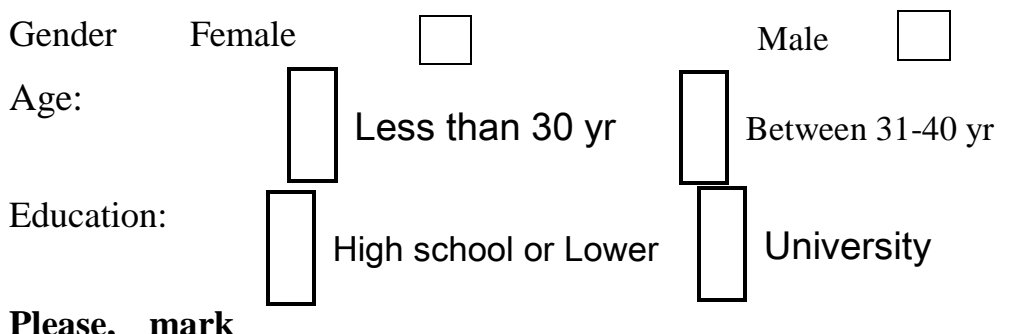

Please, mark

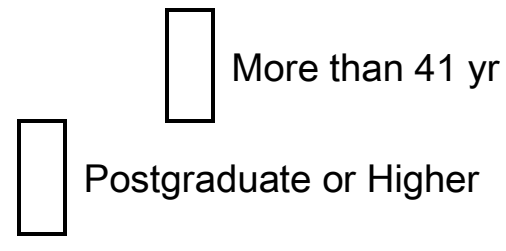

the statements that describe enterprise characteristics:

Age 
Number of Employees
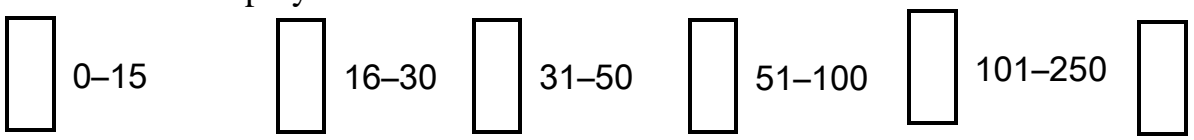
$251-500$ More than

Type of industry the enterprise belongs

Primary sector (that obtains products directly from nature, especially raw materials)

Secondary sector (that transforms raw materials into finished or semi-processed)

Tertiary sector (services sector that produces goods, services are produced)

Quaternary sector (produce highly intellectual services such as research, development, innovation \& info.)

External sector (made by enterprises involved in international commerce)

Strategic sector (Tertiary sector services sector that produces goods, services are produced)

1. Does the enterprise have being used commercial cluster platform?
Yes
No
No, (it is not necessary to answer the following questions)

Cluster, enterprises group cooperation on the same or similar market and/or complementary enterprises in order to improve commercial and services resources

2. Please, indicate the number of clusters involved that have been established by the enterprise in order to continue on the objective market:

6-12 $\begin{array}{ll}\square & \begin{array}{l}2-5 \text { Members } \\ \text { Members } \\ \text { 13-19 Members }\end{array} \quad \text { More } \square\end{array}$

3. At which moment the enterprise began to use the first commercial cluster integration network? (Please, indicate the year) Year:

4. How long have developed regional clusters commercial integration? Only with CELAC, 2011 Enterprises

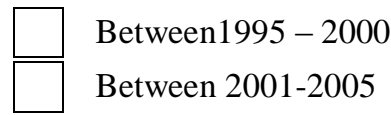

Between 2006-2010
Between 2011- 2013 (2013 included)

5. How long has developed clusters commercial integration? Only with international enterprises (not including regional enterprises).

\begin{tabular}{l}
$\square$ Between 1995-2000 \\
\hline$\square$ Between 2001-2005
\end{tabular}

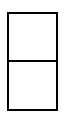

Between 2006-2010

Between 2011- 2013 (2013 included)

6. How long has developed clusters commercial integration, including international and regional enterprises?
Between

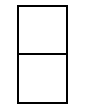
$1995-2000 \quad$ Between
Between $2000-2005$

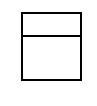
$2006-2010$
Between 2011 - 2013 (2012 included)

7. Who act as intermediaries helping to implement clusters commercial integration platform? (Can indicate more than one) 


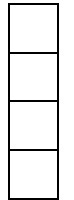

Government program/agency

Trade/professional associations Coo

Trade Publication

Financial institutes
Supply Chain Network

with others enterprises

Internet site

Venture capital enterprises

8. Of the following words, which is the most and least important to the enterprise? According to the respondent: (choose the word that best fits or less for the least fit)

1. Share Information

Growth

Be productive

Joint Venture

Market

2. Trust

\begin{tabular}{|l|l|}
\hline More & Less \\
\hline & \\
\hline & \\
& \\
\hline
\end{tabular}

Cooperation Be competitive

Commercial Cluster

\begin{tabular}{|l|l|}
\hline More & Less \\
\hline & \\
\hline & \\
\hline
\end{tabular}

\begin{tabular}{|l|l|}
\hline More & Less \\
\hline & \\
\hline & \\
\hline
\end{tabular}

\begin{tabular}{|l|l|}
\hline More & Less \\
\hline & \\
\hline & \\
\hline
\end{tabular}

Supply chain

\begin{tabular}{|l|l|}
\hline More & Less \\
\hline 1 & \\
\hline 2 & \\
\hline
\end{tabular}

9. According to the Free Trade Agreement and/or Bilateral agreements that the countries implement with other countries, the enterprises!!!!

Increase cooperation agreements at international market.

Increase internal \& external transaction cost.

Share more Information

Reduce Export size \& Cash flow

10. Please, indicate with which kind of enterprises (small, large, same size) is running clusters commercial integration.

All
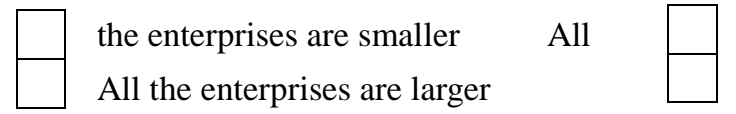

the enterprises had the same size

Some enterprises are larger and others smaller

11. Which are the reasons to implement the clusters commercial integration by the enterprise? (You can indicate more than one):

Increase production and export size

Obtain long-term agreements relating on regional or int'l marketing

Develop and increase productivity levels as well as competitiveness

Growth tech cluster relating to process research \& development

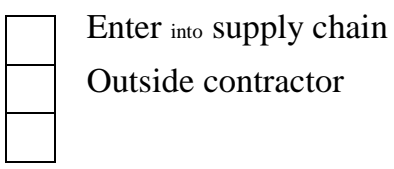

Other: specify:

12. Considering the following statements, indicate the importance of each one, at the moment that enterprise decides to establish cooperation agreement with others enterprises (can be the same region or international):

\begin{tabular}{|c|c|c|c|}
\hline$\underline{5}=$ Very Important & 1 & 3 & 4 \\
\hline The competence of the international level & & & \\
\hline The continuing of technologies advances & & & \\
\hline The reducing of products life circle & & & \\
\hline More flexible in changing a production & & & \\
\hline Other specifies $:($ & & & \\
\hline
\end{tabular}

13. Indicate in numerical form the best way to describe clusters commercial integration experiences.

\section{1 - Extremely Poor, 2 Poor, 3-Natural, 4-Good, 5- Extremely Good.}

In general, the enterprise experience with clusters has been

In general, how would characterize the financial returns produced by the enterprise on clusters commercial integration network?

In your overall assessment, how has the clusters commercial integration

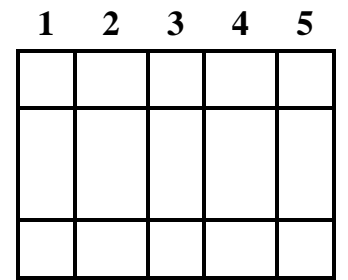


performed as comparison to your expectations?

14. In general our clusters commercial integration network platform...

\section{1-_-Strongly disagree,$\quad \underline{5}$ - S Strongly agrea}

- Provide us with truthful views of their commercial issues.

- $\quad$ Seem to feel that it is acceptable to do anything within their means that will help further their markets interest

- $\quad$ Carry out their duties even if we do not coordinate every process.

- Have sometimes promised to growth enterprise benefit without actually doing it.

- Usually register a complaint if our enterprise fails to meet commercial integration agreements

- $\quad$ Expect an equal resources benefits from our commercial integration agreement

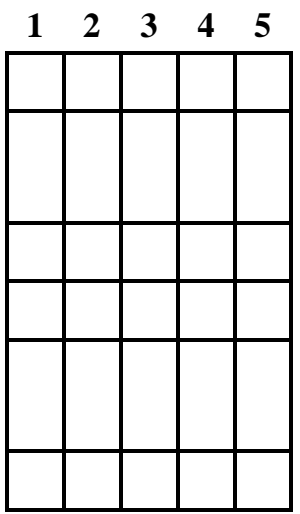

15. Please, consider the following statements related with clusters commercial integration experience. Could indicate the grade/level that best describes the enterprises during the clusters application?

\section{1_-Strongly disagrage,$\quad \underline{5}$ - S- Strongly agre}

- The cooperation agreement reduced the production costs.

- $\quad$ The cooperation agreement reduced the administration costs.

- $\quad$ The agreement permitted the small \& medium enterprises a commercial integration have not control.

- The commercial integration agreement will establish between similar commercial culture enterprises.

- $\quad$ The commercial integration agreement will not establish with productive $\&$ competitive enterprises.

- The agreement will reduce enterprise investment requirement

- The agreement constitutes better option for initiating the international expansion.

- $\quad$ The commercial integration agreement will affect in negative level the enterprises reputation.

- The enterprises that participate in a commercial integration agreement must to have similar objectives.

- The trust level between networking enterprises is fundamental on commercial integration establishment.

16. Can order the following possible issues, since the most important to the less important?

$\begin{array}{lllll}1 & 2 & 3 & 4 & 5\end{array}$

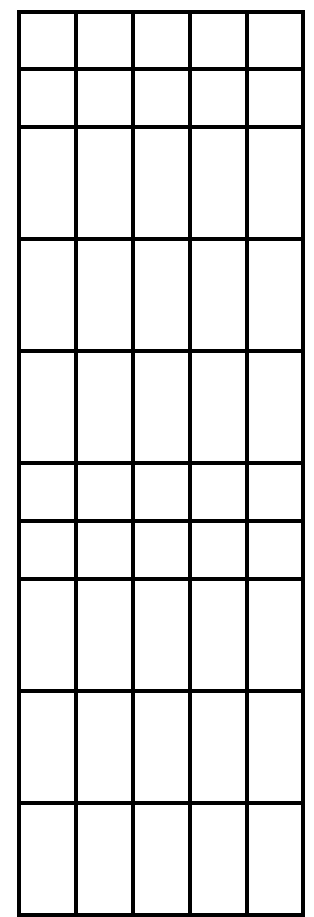

\section{1 -_Very unimportant, $\quad 5$ - - Very_important}

- $\quad$ The high competition between network enterprises occurred problems in commercial integration and its implementation.

- Has shown the need to get more profits and have more advantages in the network enterprise platform

- $\quad$ Culture \& ethics differences obstacle was and misunderstanding in commercial integration network \& its implementation.

- Have appeared to alter the facts slightly in order to get what they need.

- Sometimes do not protect the interest/advantage of enterprises network.

- Other (specify)...

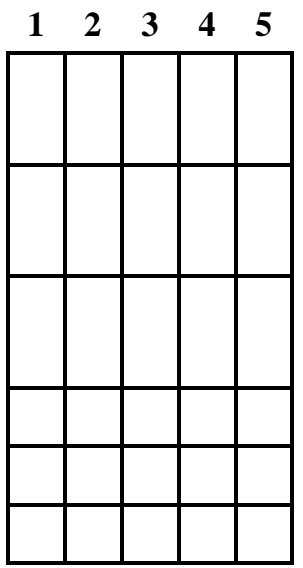

